\title{
ANALISIS BANJIR BANDANG DENGAN MENGGUNAKAN DATA CITRA SATELIT DI KABUPATEN LUWU UTARA (STUDI KASUS 13 JULI 2020)
}

\author{
${ }^{1)}$ Rino Wijatmiko Saragih \\ ${ }^{1)}$ Badan Meteorologi Klimatologi dan Geofisika - Stasiun \\ Meteorologi Karel Sadsuitubun Maluku Tenggara \\ Email: rinosaragih14@gmail.com
}

\begin{abstract}
Flash floods that hit parts of South Sulawesi on July 13, 2020, left 36 people dead, 18 people lost, 40 people missing, 58 injured, and a total of 14,483 people were affected. Around 14,000 people were evacuated to safer locations due to not having a home to live in. The disaster was caused by heavy rains. One of the areas affected was North Luwu. This phenomenon needs to be done research so that people can overcome the possibility of disasters that might occur. Air pressure and air temperature for 2 days before the occurrence of flash floods have the same relative patterns and anomalies occurred on the day of the incident. This research uses satellite image data interpretation method by processing the Himawari-8 infrared channel data and compared with rainfall data from the Andi Jemma meteorological station in North Luwu Regency on July 13, 2020. Interpretation and analysis of satellite imagery data shows the growth of strong convective clouds has the potential to cause rain in North Luwu around 07.00 UTC. So it was concluded that during a flash flood, unstable atmospheric conditions and the presence of Cumulonimbus (CB) cloud cover in the North Luwu region
\end{abstract}

Key word: Flash Floods, Himawari-8, Satellite.

\section{PENDAHULUAN}

Banjir bandang yang terjadi di Luwu Utara, Sulawesi Selatan pada tanggal 13 Juli 2020 cukup banyak menelan korban, baik jiwa maupun harta. Berdasarkan data Badan Nasional Penanggulangan Bencana (BNPB), per tanggal 18 Juli 2020 bencana tersrbut telah merenggut sebanyak 36 orang tewas, 40 orang hilang, luka-luka 58 orang, dan total korban terdampak $3.627 \mathrm{KK}$ atau 14.483 jiwa (Kompas, 20 Juli 2020). Pemerintah menyatakan bahwa salah satu factor penyebab banjir bandang ini adalah factor alam yaitu intensitas hujan yang tinggi. Penyebab lainnya adalah pengalihan fungsi lahan dan adanya sejarah patahan yang mengakibatkan kondisi formasi di
Kawasan hulu lemah, yang mengakibatkan mudah terjadi longsor. Negara Indonesia merupakan negara kepulauan terbesar di dunia dengan wilayah perairan sekitar $70 \%$ dan daratan hanya $30 \%$. Sebagai negara maritim yang dilalui ekuator, Indonesia selain menerima insolasi dalam jumlah besar, juga memperoleh panas laten kondensasi perubahan fasa uap menjadi air cair sekitar $2450 \mathrm{~J} / \mathrm{g}$. Di atas Indonesia awan konvektif lebih dominan ketimbang awanawan jenis lain (Bayong, 2006). Sistem cuaca wilayah Indonesia terpengaruh dari fenomena cuaca global seperti MJO (Madden-Julian Oscilation), SOI (Southern Oscilation Index), suhu muka laut, IOD (Indian Ocean Dipole), fenomena cuaca regional seperti pola tekanan udara, pola 
suhu udara dan fenomena cuaca lokal. Banjir biasanya terjadi akibat luapan air sungai karena kapasitas tampungannya tidak memadai atau rusaknya tanggul dan akibat adanya genangan air karena topografinya rendah sehingga air tidak lancar masuk ke sungai (Djajadiredja, 2006). Selain itu juga, jumlah curah hujan memainkan peran penting terhadap distribusi geografi terkait banjir ekstrem (James, 2000).

Penelitian ini bertujuan untuk mengindetifikasi fenomena banjir bandang dengan menggunakan aplikasi SATAID (Satellite Animation and Interactive Diagnosis) yang dapat menginterpretasikan data parameter meteorologi dari citra satelit pada kanal Infra Red (IR), kemudian dilakukan pengolahan menggunakan aplikasi SATAID, selanjutnya dilakukan interpretasi kualitatif secara visual dari citra satelit untuk menentukan suhu awan dari citra satelit dan data pengamatan udara permukaan (sinoptik) serta fenomena cuaca skala global.

\section{METODE}

Metode yang digunakan dalam penelitian ini meliputi menganalisis cuaca harian pada tanggal 13 Juli 2020 di Kabupaten Luwu Utara untuk melihat faktor penyebab cuaca buruk yang terjadi. Setelah itu dilanjutkan dengan proses interpretasi dari data satelit Himawari-8 pada tanggal 13 Juli 2020 dengan pengolahan data infrared channel dalam perangkat lunak SATAID (GMSLPD) untuk menampilkan nilai suhu puncak awan. Menganalisis curah hujan berdasarkan data sinoptik stasiun meteorologi Andi Jemma tanggal 13 Juli 2020 .

\section{HASIL DAN PEMBAHASAN}

Hasil Analisis Cuaca Harian MJO atau disebut juga osilasi intraseasonal MJO, adalah elemen terbesar dari variabilitas intraseasonal dengan periode 30-90 hari di atmosfer wilayah tropis,dengan karakteristik utama yakni adanya wilayah peningkatan dan penurunan curah hujan yang bergerak berpasangan mengelilingi bumi dari barat ke timur, dan umumnya terjadi di sepanjang Samudera Hindia hingga Samudera Pasifik.( Madden dan Jullian , 1994) Karakteristik MJO dikaji lebih dalam dengan menggunakan struktur 3 dimensi yaitu ketika suppressed convective kuat dari lautan Hindia hingga lautan Pasifik Tengah, anomali siklonik pada level $200 \mathrm{mb}$ bergerak mengikuti daerah dari suppressed convective.(Rui dan Wang, 1990). Terdapat empat kelompok fase sesuai dengan pewilayahan diagram fase MJO pada Gambar 1.1 , yaitu fase $8 \& 1$ di Western Hemisphere and Africa, fase $2 \& 3$ di Indian Ocean, fase $4 \& 5$ di Maritime Continent, fase 6\&7 di Western Pacific. (Wheeler dan harry, 2004). Berdasarkan data MJO (MaddenJulian Oscillation) pada saat kerjadian banjir bandang, MJO dikategorikan aktif tetapi berada pada fase 2 , yang menandakan bahwa pada saat MJO aktif di fase 2 \& 3 berpengaruh pada wilayah Samudra Hindia, serta memiliki efek yang kuat karena berada di luar lingkaran bulat, dapat dilihat pada garis biru di gambar 1. Berdasarkan data SOI (Southern Oscillation Index), SOI bernilai $+4,7$ yang berarti tekanan udara di Tahiti lebih tinggi daripada di Darwin sehingga terjadi pergerakan massa udara dari Samudra Pasifik Timur ke Pasifik Barat di Wilayah Indonesia terjadi penambahan uap air. 


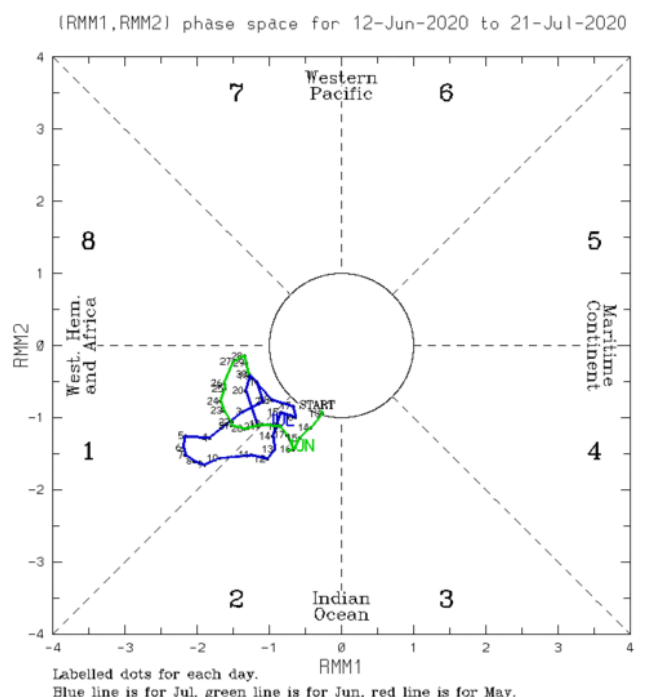

Gambar 1. Fase MJO 12 Juni -21 Juli 2020

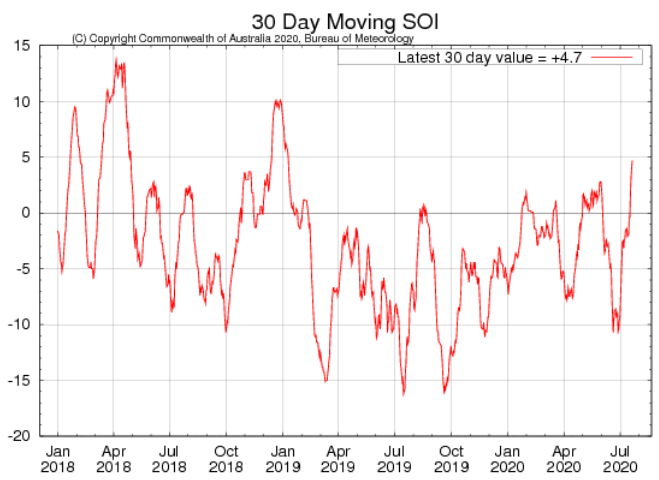

Gambar 2. Indeks SOI Januari 2018-Juli 2020

Kondisi suhu muka laut (sea surface temperature) pada saat tanggal 13 Juli 2020 pada pukul 00.00 UTC (08.00 WITA) sekitar antara $30^{\circ} \mathrm{C}-32^{\circ} \mathrm{C}$. pada pukul 12.00 UTC (20.00 WITA) suhu muka laut menunjukan nilai yang sama.
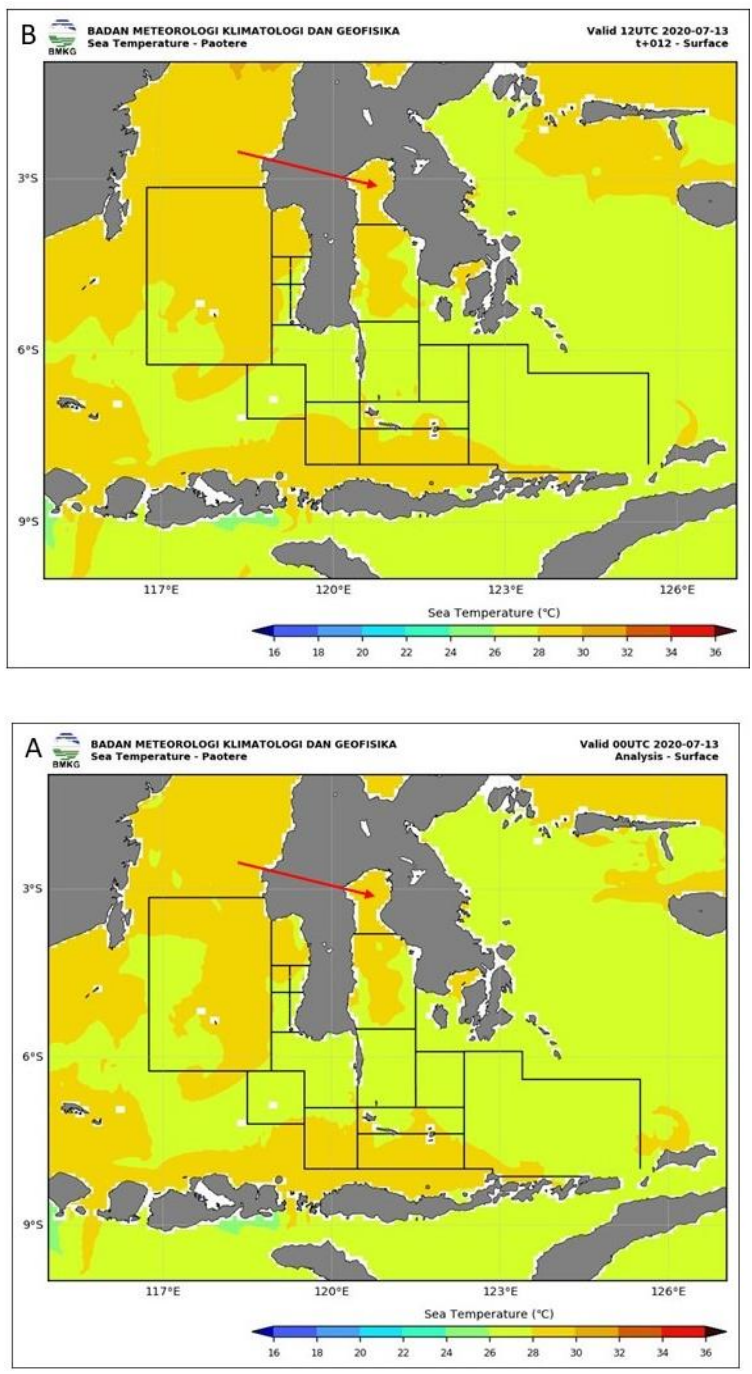

Gambar 3. Suhu muka laut pada tanggal 13 Juli 2020 (A) pukul 00.00 UTC dan (B) 12.00 UTC

Gradien angin pada saat kejadian banjir bandang pada tanggal 13 Juli 2020 pada pukul 00.00 UTC dan 12.00 UTC menunjukan divergensi. Angin di wilayah Luwu Utara, dominan bertiup dari Tenggara, namun terdapat belokan angin disebelah barat pulau Kalimantan, sehingga dapat mempengaruhi keadaan cuaca di wilayah tersebut. 

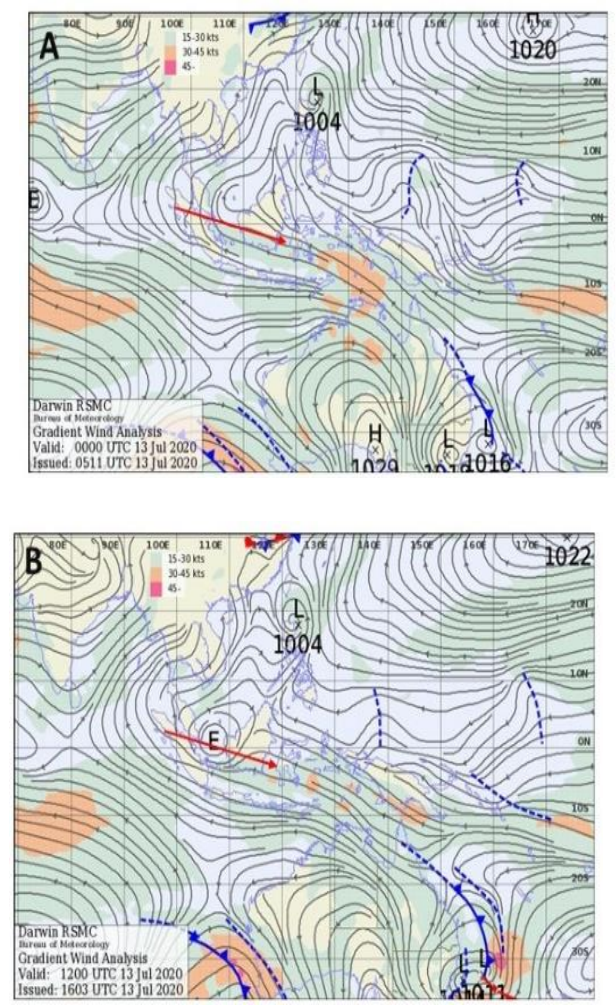

Gambar 4. Kondisi angin gradien pada taggal 13 Juli 2020 gambar A pukul 00.00 UTC (08.00 WITA) dan gambar B pukul 12.00 UTC (20.00 WITA)

\section{Hasil Analisis Kondisi Sinoptik}

Pada kondisi Analisis sinoptik pada tanggal 11, 12 dan 13 Juli 2020 di tampilkan kondisi suhu udara dan tekanan udara. Data sinoptik ini diambil dari website bmkgsoft BMKG yang diambil dari Stasiun Meteorologi Andi Jemma - Luwu Utara. Dari Hasil Analisis tekanan terdapat perbedaan tekanan pada saat tanggal kejadian dibandingkan dengan kondisi cuaca dua hari sebelum terjadinya banjir bandang. Peningkatan tekanan udara terjadi pada tanggal 13 Juli 2020, namun perbedaan tekanan tersebut tidak terlalu signifikan. Berikut merupakan tabel tekanan udara pada tanggal 11, 12 dan 13 Juli 2020.
Tabel 1. Kondisi Tekanan Udara

\begin{tabular}{|l|l|l|l|}
\hline \multirow{2}{*}{$\begin{array}{l}\text { Jam } \\
(\text { UTC })\end{array}$} & \multicolumn{3}{|l|}{ Tanggal } \\
\cline { 2 - 4 } & 11 & 12 & 11 \\
\hline 06.00 & 1008.2 & 1008.1 & 1008.5 \\
\hline 07.00 & 1007.8 & 1007.7 & 1008.0 \\
\hline 08.00 & 1008.0 & 1007.8 & 1008.7 \\
\hline 09.00 & 1008.6 & 1008.0 & 1009.2 \\
\hline 10.00 & 1009.3 & 1008.6 & 1009.9 \\
\hline
\end{tabular}

Pada Analisis suhu udara saat kejadian banjir bandang terjdi penuruan suhu udara. Suhu udara berbeda pada saat dua hari sebelum kejadian. Terjadi penurunan suhu udara hingga $3{ }^{\circ} \mathrm{C}$ pada tanggal 13 Juli 2020 dan 11 Juli 2020 pada pukul 09.00 UTC. Kondisi cuaca berdasarkan hasil pengamatan sinoptik adalah hujan. Untuk curah hujan yang terukur pada pukul 09.00 UTC atau jam 17.00 WITA berdasarkan hasil pengamatan stasiun meteorologi Masamba adalah 27,2 $\mathrm{mm}$

Tabel 2. Kondisi Suhu Udara

\begin{tabular}{|l|l|l|l|}
\hline \multirow{2}{*}{$\begin{array}{l}\text { Jam } \\
\text { (UTC) }\end{array}$} & \multicolumn{3}{|l|}{ Tanggal } \\
\cline { 2 - 4 } 06.00 & 11 & 12 & 11 \\
\hline 07.00 & 29.4 & 29.8 & 29.5 \\
\hline 08.00 & 28.4 & 29.6 & 28.3 \\
\hline 09.00 & 28.2 & 29.1 & 25.3 \\
\hline 10.00 & 28.4 & 28.4 & 25.2 \\
\hline
\end{tabular}

Hasil Analisis Interpretasi Citra Satelit Dari data citra satelit tanggal 13 Juli 2020, data tersebut kemudian diolah menggunakan aplikasi SATAID versi GMSLPD yang memiliki fitur analisis untuk tropical cyclone. Analisis dari citra satelit menunjukkan pertumbuhan awan konvektif kuat yang berpotensi menimbulkan hujan di daerah Luwu Utara. Awan mulai memasuki area wilayah Luwu Utara pada pukul 04.00 UTC terlihat pada gambar 5 A. Tutupan awan mulai memasuki wilayah Luwu Utara terjadi pada pukul 07.00 UTC atau 15.00 WITA terlihat pada gambar $5 \mathrm{D}$. Tutupan 
awan hujan tersebut masih menutupi wilayah Luwu Utara hingga pukul 09.00 UTC atau 17.00 WITA.

Pada gambar 6, masih terdapat tutupan awan yang dapat menyebabkan hujan di wilayah Luwu Utara hingga pukul 12.00 UTC atau 20.00 WITA. Tutupan awan mulai menjauhi wilayah Luwu Utara pada pukul 13.00 UTC gambar D dan mulai hilang pada pukul 14.00 UTC gambar E. Tutupan awan ini memiliki durasi yang cukup lama yaitu kurang lebih 6 jam, dari pukul 07.00 UTC hingga 12.00 UTC.
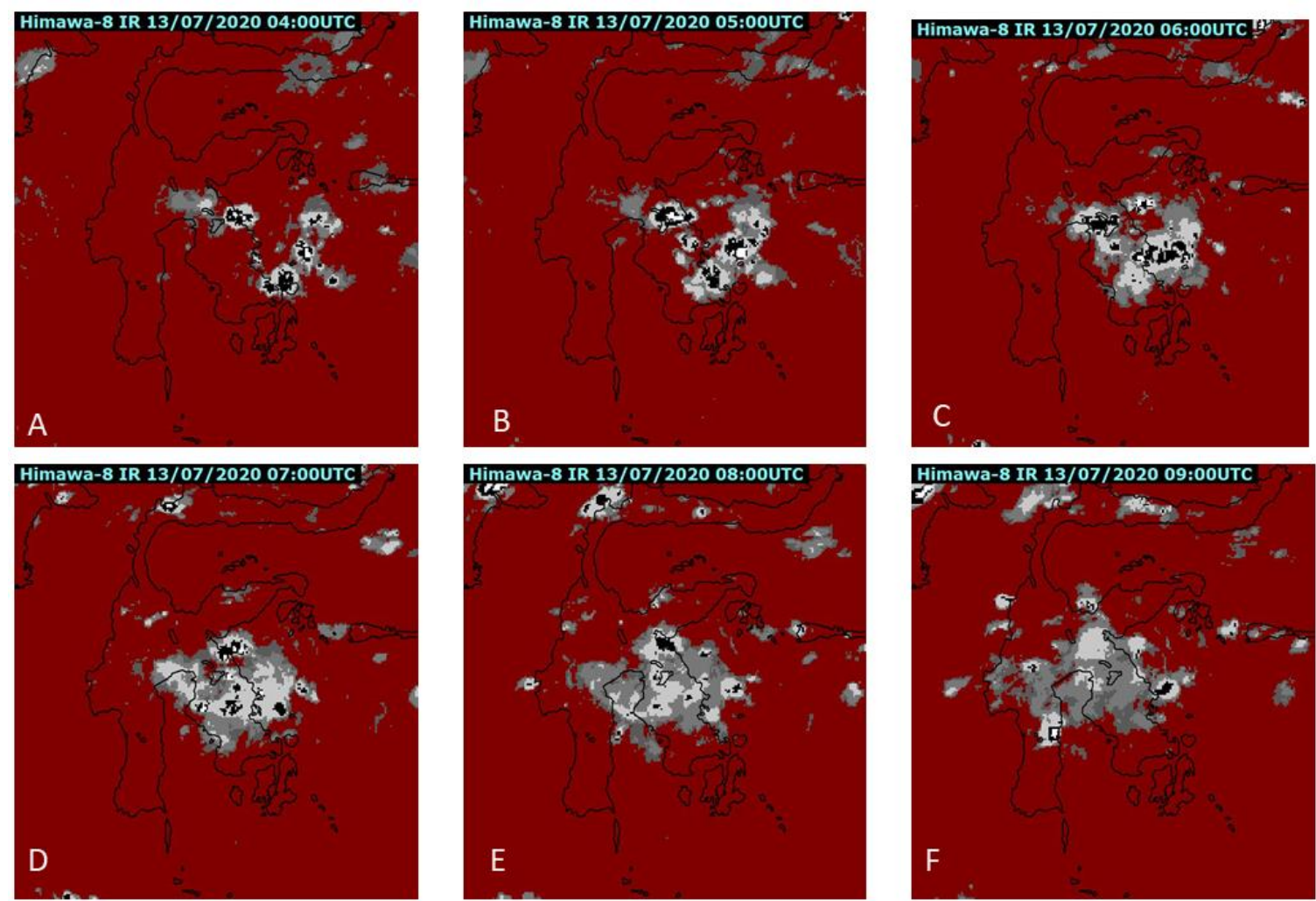

Gambar 5. Kondisi tutupan awan di wilayah Luwu Utara dari citra satelit Himawari-8 

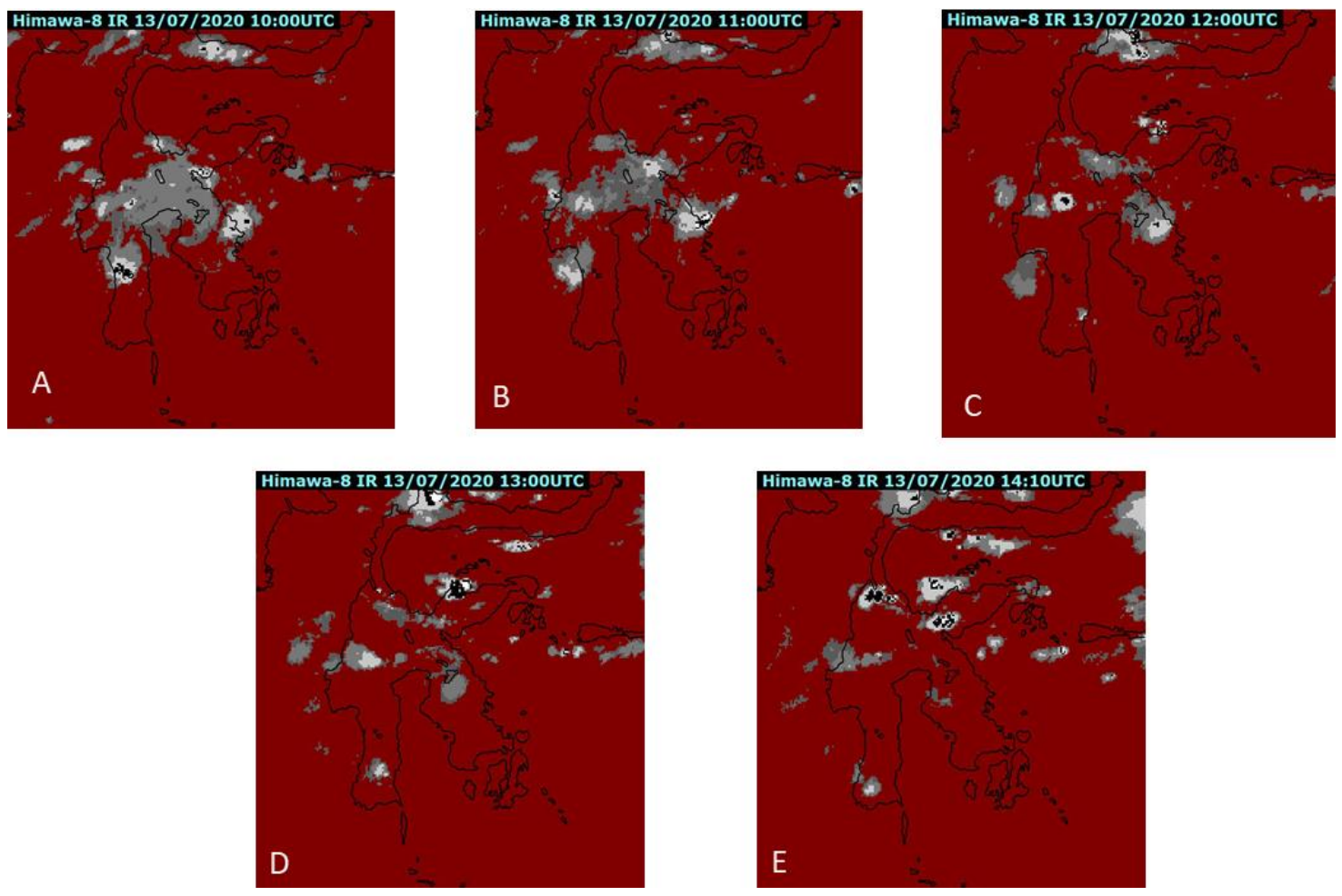

Gambar 6. Kondisi tutupan awan di wilayah Luwu Utara dari citra satelit Himawari-8 pukul 10.00 UTC - 14.00 UTC

\section{SIMPULAN DAN SARAN}

Berdasarkan Analisis diatas dapat disimpulkan bahwa banjir bandang yang terjadi di wilayah Luwuk Utara pada tanggal 13 Juli 2020 di sebabkan oleh faktor cuaca. Tutupan awan hujan yang di patau melalui citra satelit Himawari-8 menunjukan bahwa pada pukul 07.00 UTC sampai 12.00 UTC. Tutupan awan tersebut mengakibatkan hujan dibeberapa wilayah di Luwuk Utara. Pembentukan hujan terjadi pada awan-awan yang mempunyai suhu puncak yang rendah (Handoko, 1994). Awan-awan rendah umumnya suhunya lebih hangat dan berada relative dekat terhadap permukaan bumi, sementara awan-awan bersuhu lebih dingin merupakan jenis awan-awan tinggi (BMKG, 2010).
Kondisi Analisis cuaca pada saat kejadiaan banjir bandang di Luwu Utara seperti MJO kurang mendukung diakibatkan berada pada fase 2, sehingga kurang mendukung untuk pembentukan awan hujan di wilayah tersebut. Analisis suhu permukaan laut pada tanggal 13 Juli 2020 disekitar area Luwu Utara berkisar antara $30{ }^{\circ} \mathrm{C}-32{ }^{\circ} \mathrm{C}$. Untuk pola gradien angin pada wilayah Luwu Utara terdapat pola angin divergensi pada pukul 12.00 UTC, hal itu mengakibatkan awan hujan mulai menjauhi wilayah Luwuk Utara. Kondisi sinoptik pada saat terjadinya banjir bandang dibandingkan dengan dua hari sebelum kejadian terdapat penurunan suhu udara dan terjadi penaikan tekanan udara. Sehingga salah satu faktor terjadinya banjir bandang di Luwu utara adalah adanya hujan di wilayah tersebut 


\section{DAFTAR PUSTAKA}

BMKG (2010), Keputusan No.009 Tentang

Prosedur Standart Operasional

PelaksanaanPeringatan Dini,

Pelaporan, dan Diseminasi Informasi

Cuaca Eksrem, BMKG, Jakarta.

Djajadiredja, Eddy A. (2006), Pena Kearifan

Lokal dan Teknologi dalam Mencari

Solusi Bencana Banjir Bandang,

BPPT, Jakarta

Handoko (1994), Klimatologi Dasar, Pustaka Jaya, Jakarta.

Kompas (2020),

https://www.kompas.com/sains/read/20

20/07/21/080933623/bmkg-jelaskan-

banjir-bandang-luwu-utara-tidak-

berkaitan-dengan-gempa?page $=$ all

(diakses : 23 Juli 2021)

James, A. Smith, Lynn Baeek, Julia E., Morrison, Paula Sturdevant-Rees. (2000), Catastophic Rainfall and Flooding In Texas, The Jurnal American Meteorological Society Vol.1.

Madden, R.A., Jullian, P.R. 1994..

Observations of the 40-50-Day Tropical Oscillation - A Review. Monthly Weather Review, 122(5), 814-837. doi: 10.1175/15200493(1994)1222.0.CO;2

Rui, H. \& B. Wang.1990.Development characteristics and dynamic structure of tropical intraseasonal convection anomalies. J Atmos Sci, 47, 357-379.

Tjasyono H.K., Bayong, dan Harijono, Sri Woro B., 2006, Meteorologi Indonesia Volume II, BMG, Jakarta

Wheeler, Matthew C., and Harry $\mathrm{H}$. Hendon.2004. An all-season real-time multivariate MJO index: Development of an index for monitoring and prediction. Monthly Weather Review 132.8: 1917-1932. ma. 5(2). 